\title{
Flipping The Business College On Its Side
}

Dallas Brozik, Marshall University, USA

Chris Cassidy, Sam Houston State University, USA

\begin{abstract}
Colleges of business are typically formed around functional divisions like accounting, finance, management, and marketing. This discipline-based structure serves to convey basic information to the students, but it is poorly suited to provide an educational experience that integrates the functional areas into a holistic framework. Efforts to refine the educational process have met with limited success due to the tendencies of organizations and their members to resist change. A new design for the structure and management of colleges of business is necessary if today's schools are to be better able to meet the needs of tomorrow's students.
\end{abstract}

Keywords: Curriculum; Integration; Multidisciplinary; College Organization

\section{INTRODUCTION}

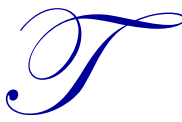

he challenge in higher education is to provide students with a broad liberal background that will prepare each student to be able to interact with an increasingly complex world. The challenge faced by colleges of business is to provide students with the necessary skills to succeed in the business world while universities achieve their general educational goals. Universities and colleges are structured to meet these educational goals, but as the societal environment changes, the established structures of the institutions may not be robust or resilient enough to meet the needs of modern students.

There are many ways that organizations can structure themselves and the structure chosen will have a direct bearing on the effectiveness of the organization to achieve its goals. Universities and colleges have traditionally organized themselves according to functional disciplines. The field of strategic management demonstrates that organizational strategy dictates organizational structure (Chandler, 1962), and there is ample reason to believe that colleges of business have adopted their structure from the functionally organized businesses they study (DiMaggio \& Powell, 1983). While this structure may be appropriate for giving students the opportunity to develop highly specialized knowledge and skills, it may not be able to deliver the interdisciplinary education necessary to coordinate the resource deployments across the functional areas of business and demanded in today's market.

\section{BACKGROUND}

Business is a "big" concept. A successful business, large or small, must be able to conduct all aspects of the operation at an appropriate level to be successful. Accounting, finance, management, and marketing are all interwoven in the complex pattern of activities and problems that a business must face each day (Hitt, Ireland, \& Hoskisson, 2000). Each day brings a different set of challenges that often require a new or adaptive approach. No two days are the same, and no two problems look alike. Business managers must use interdisciplinary approaches every day.

The inherent problem with trying to teach a "big" subject is that it is big. It is difficult to develop an introduction to such material without overwhelming the student. People new to the field of business may have the best intentions and the intellectual capacity to succeed, but the process of integrating such a massive amount of information can prove daunting. Pieces of the puzzle that are small enough to understand are incomplete in scope.

Businesses divide their market-based activities into functional areas for ease of management. Colleges of business have historically adopted this model and divided the teaching of business into functional departments. This traditional approach has created somewhat artificial barriers between the various aspects of the business experience. 
Accounting, finance, management, and marketing activities are often isolated and taught as separate and distinct disciplines. The creation of "silos" permits specialization to occur, and the practitioners in these respective areas can create techniques and methods to teach the specialized material. The problem is that in doing so, the integrative nature of the material is lost or, at best, marginalized. Students are not taught "business"; they are taught "pieces of business".

\section{LITERATURE REVIEW}

The study of business as a distinct academic discipline is only about 100 years old. Bohanon (2008) reviews the historical roots of colleges of business and notes that in the late 1800s students who would be going into business enrolled in only those courses they felt were relevant to their specific needs and did not complete a degree. The first business schools were formed so that the children of businessmen could learn material bearing on their future business activities while still pursuing a liberal education. From the start, business schools were hybrids that integrated the liberal arts core with the demands of contemporary business conditions.

Business education, by its very nature, has an embedded objective concerning the employability of the students (Junghaven, 2005). Close relations with the business community are important, and the curriculum must be designed to meet the needs of the future graduates. Faculty members must be able to work in a multidisciplinary environment, and the goals of teaching, research, and service cannot be regarded as independent dimensions of the profession.

Many of the difficulties with designing an appropriate business core are also present when designing a general education core for the university. Traditional approaches often involve well-meaning individuals who try to modify the existing system rather than advocate wholesale change (Hubball \& Gold, 2007). This results in a continuation of a curriculum which fails to address learning styles or the needs of the students. Students are expected to make sense of the program presented to them, a program which is disconnected from the ultimate goals of the students and the educational objectives of the institution. This disconnect between organizational goals and the organizational structure required to achieve those goals is a persistent problem for the managers and educators responsible for creating an organizational strategy to achieve those goals (Barney, 2002; Chandler, 1962; Hitt, et al., 2000).

Peach (2010) noted that when the goals of the curriculum are linked to professional development they are more likely to result in more career opportunities, greater personal economic security, and a higher level of personal fulfillment. Many students do understand the need for a multidisciplinary background as evidenced by the number of students who are double majors. They have recognized that a single skill set will not be enough to insure success. Taff (1988) suggests that by changing curriculum requirements, students could graduate with triple majors and thus present potential employers with an even broader skill set.

A broad-based integrated curriculum helps provide students with an understanding of the relationships between the various disciplines (Athavale, Davis, \& Myring, 2008). One of the most common methods of teaching across the disciplines within the structure of a traditional curriculum is to use case studies. A variant on this approach is to develop modular courses that address several disciplines. Another approach to cross-disciplinary education is the use of scenarios (Bracken, 2008). Scenarios focus on future possibilities rather than past experiences and add another dimension to the analytical problem and learning potential.

There are many different approaches to broaden the curriculum across various dimensions. Interdisciplinary courses, team taught by business and liberal arts faculty, have been demonstrated to improve students' understanding of international issues (Smith, Hornsby, \& Kite, 2000). Interdisciplinary courses that expose students to cross-functional material have been shown to improve critical thinking skills (Braun, 2004). Development of a first-year seminar in the general education curriculum has also met with success (Pittendrigh, 2007). Other techniques used to promote curriculum integration include writing across the curriculum, critical thinking, and increased computer usage. These methods are skill-based and require few additional resources. Programmatic methods, like additional majors and minors, and integrative interdisciplinary courses can require a significant commitment of resources (Hill, 1990). 
The establishment of integrated course offerings presents its own set of challenges. All stakeholders must be involved with and support the concept (Pharr, 2000). Students must be willing to take integrated courses which may be perceived to be more rigorous and thus threatening to grade point averages. Faculty members must be willing to move beyond their functional expertise and invest the time to make integrated courses a success, and a reward structure must be established to ensure that faculty ratings are not adversely affected. As with the institution's general education curriculum, the "guild interest" of faculty must also be overcome (Brint, Proctor, Murphy, Turk-Bicakci, \& Hanneman, 2009). The administration must provide the needed resources of time, space, and funding. All of this must be done under the existing institutional mission statement in accordance with specified objectives.

Albert Einstein said "We cannot solve our problems with the same thinking we used when we created them." The one thing that is common to all approaches to revising the curriculum is that they are evolutionary in nature. The concept of changing the organizational structure of the college is rarely discussed. The organizational structure itself could be hindering the ability of colleges of business in their efforts to deliver interdisciplinary courses that give students the multidisciplinary skill set they will need for success.

\section{TODAY'S COLLEGE OF BUSINESS}

The structure of the modern college of business is the result of heritage decisions made over the last century. The formative decision was to break down the business experience into functional areas, or silos (Figure 1). Accounting has been around for thousands of years, and in the $20^{\text {th }}$ century, the disciplines of finance and management information systems (MIS) branched out from this base. Management and marketing were two widely understood concepts of the experience, and there was a sufficient body of knowledge to permit their separation into distinct functional areas. Economics was brought into the fold to give a theoretical rationale and underpinning for the decisions made in the specific disciplines.
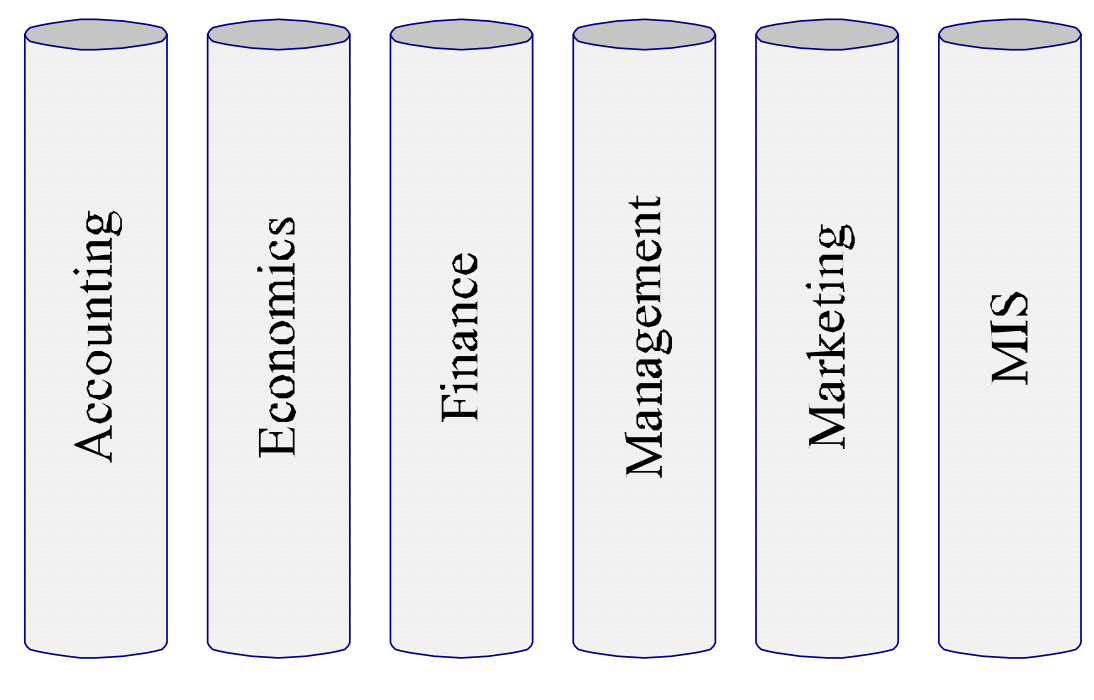

Figure 1: Functional Silos

The specialized nature of the "siloed" subject matter allowed instructors to develop high levels of expertise in each area. While expertise is good to have, when it comes at the cost of teaching students the multidisciplinary skills necessary for the business world, the price may be too high to pay. Students could learn highly detailed knowledge concerning restricted subject matter but be unable to apply that knowledge in a real-world framework due to a lack of knowledge about how their individual expertise interfaced with the broader needs of business. The establishment of the common business core did improve the students' ability to understand concepts relating to business from outside their designated area of expertise. It became possible for instructors to broaden the scope of their courses with the understanding that students had been exposed to material from the other functional silos; but 
integration of the subject material was still the responsibility of the student. The common core provided the base upon which the silos were built (Figure 2)

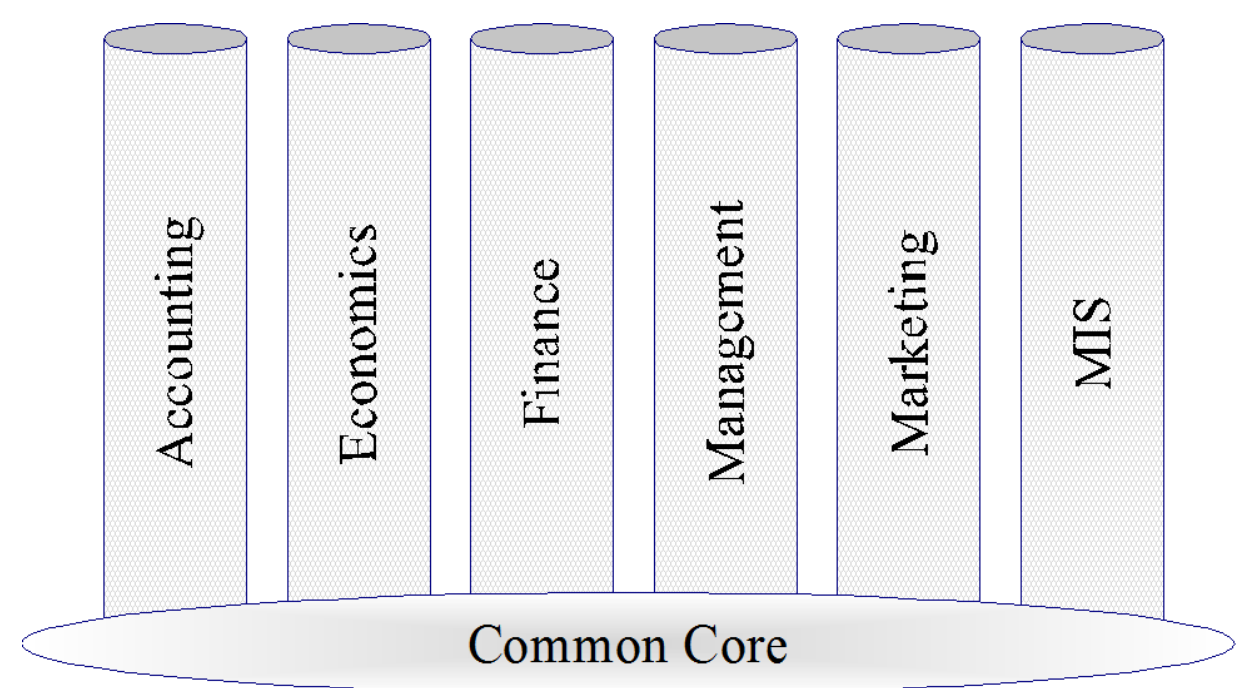

Figure 2: Silos and the Common Core

The next step in developing a multidisciplinary curriculum was to develop capstone courses in the various disciplines (Figure 3).

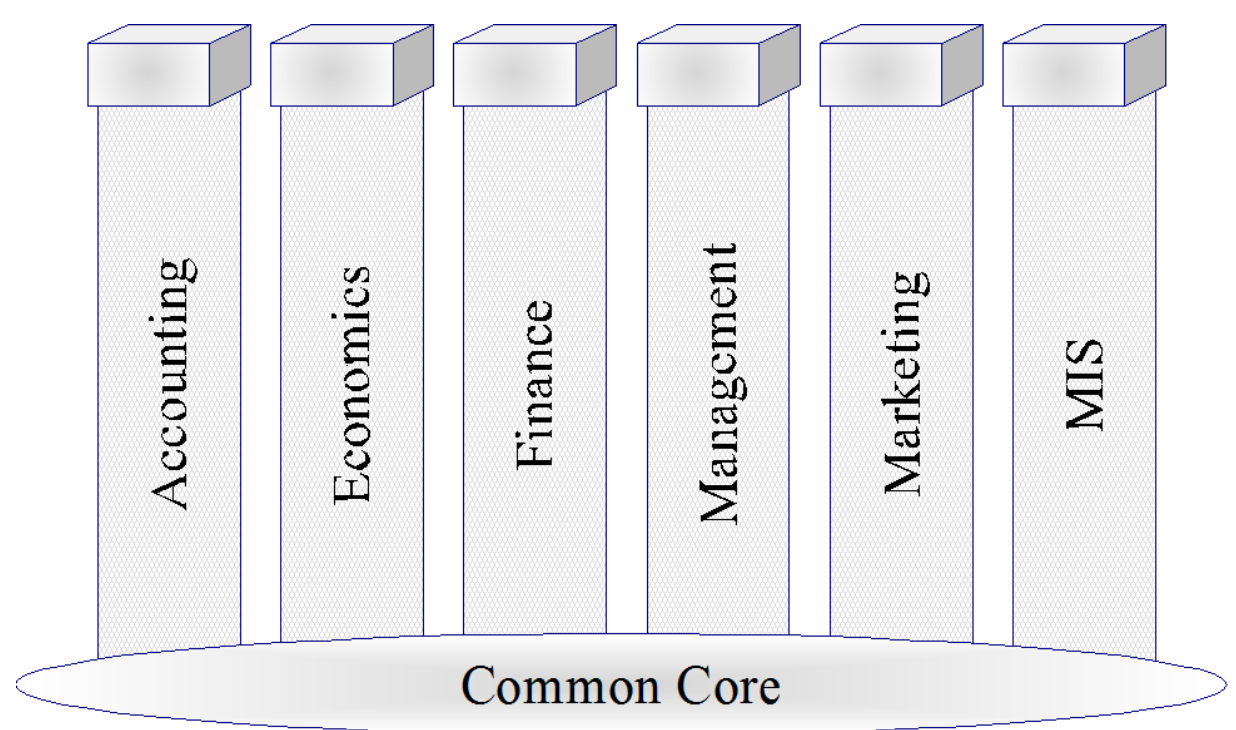

Figure 3: Silos with Functional Capstones

The success or failure of these disciplinary capstones was determined by the abilities of the instructor of the course. If the instructor had a broad educational and experiential background, these courses could often be quite effective in teaching how the different functional disciplines interacted in a business situation. Instructors with a more specialized background could make good faith attempts to bring in material from the other areas, but the experiential "glue" that held the different concepts together could be missing. 
The use of case courses attempts to address the issue of the breadth of coverage. A properly designed case can bring in aspects of other functional areas while still addressing the main subject area. Careful selection of cases for the course permits the introduction of concepts from all other functional areas during the course of study. Students are given an exposure to the major points of the various functional areas and how they interact with the specialized silo, but that exposure is still from the viewpoint of a specific functional discipline.

A well-taught disciplinary capstone course can provide students with an exposure to the overall business experience, but these were still not truly multidisciplinary in nature. An instructor from a functional silo may provide cross-disciplinary training, but the course would still be oriented toward the instructor's functional silo. A capstone course in finance could indeed address issues other than finance, but the major underlying themes would be financial in nature. The underlying problem is that a functional capstone course is still functional in nature and lacks the framework to address the whole spectrum of business. The addition of a college-wide capstone course was seen to be the solution to this problem (Figure 4).

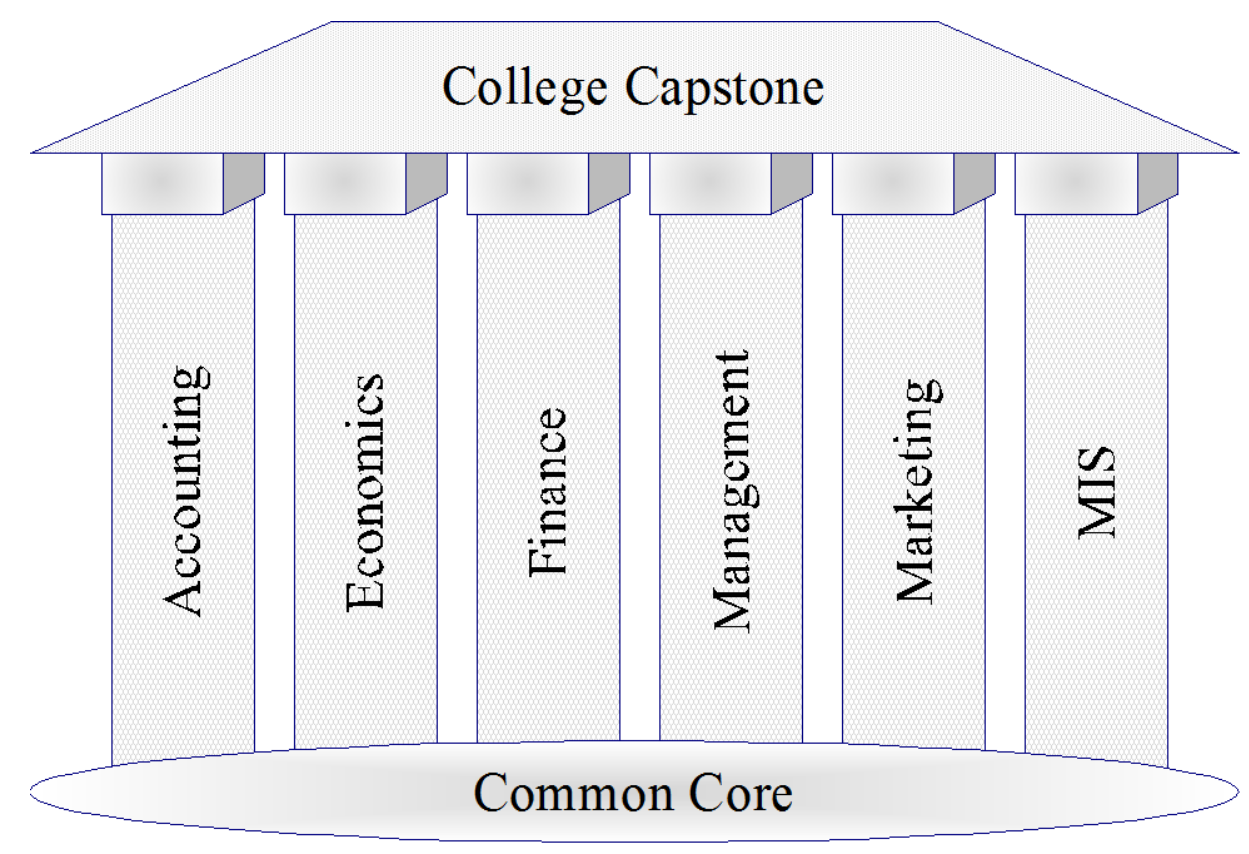

Figure 4: Silos with College Capstone

The addition of the integrative capstone course as the solution to the lack of multidisciplinary education is itself problematic. Integrative courses may have a broader management flavor, but many of the details of the functional areas can be lost. Another alternative is to use a Business Policy and Strategy (BPS) course as the capstone. The emphasis of BPS courses is overall organizational performance from the perspective of CEOs and other senior managers. This approach provides broad oversight and integration across functional specialties but fails to provide true understanding of the details needed to break down silo walls across specialties.

One method of creating a truly multidisciplinary capstone experience would be to use a modular approach. A course could be designed around case courses, each dealing with a specific functional area. Instructors from each discipline could rotate through the several modules of the course to assure that each group of students received the same exposure to the same body of material. While this would address the breadth of the problem, it would still not assure the integration of the material. A capstone course could be team taught by several faculty members simultaneously in the classroom, but the seemingly endemic shortage of qualified business faculty would create a problem with manning and scheduling. 
It is still necessary to create a truly multidisciplinary experience into the capstone. This experience would necessarily involve faculty from several disciplines working with the students at the same time. Such an experience might not be compatible to traditional classroom instruction. One method could be to create an internal competition at the end of the semester. Students from all classes could be given a broadly-based case and given a week to prepare their analysis. During this time, the various instructors could interact with the different student groups to answer questions and provide guidance. After the case has been prepared by the several student groups, it could be presented to a panel of judges, not necessarily all from the business school, and the students could be rated on their analysis and their presentation ability.

All of these proposals have merit, but they are all based on working within the existing organizational design. They are evolutionary in nature. A century of evolution in the educational organization has not resulted in a century of progress. The tendency to design for continuity has resulted in organizational structures that become increasingly better at addressing the problems of the past. If the college is to address the problems of the future, a more revolutionary approach might be appropriate.

\section{DESIGNING THE COLLEGE OF BUSINESS OF TOMORROW}

Colleges face problems beyond the creation of multidisciplinary education. Recruitment and retention of faculty are real problems in today's environment. The faculty is aging and replacements are both hard to find and expensive. Budgets will continue to be strained for the foreseeable future. Under these conditions, it is appropriate to examine the structure of the college to determine if it is still able to meet today's challenges. These and other problems can be addressed by flipping the silos on their sides to remove artificial barriers and eliminate the silos (Figure 5).

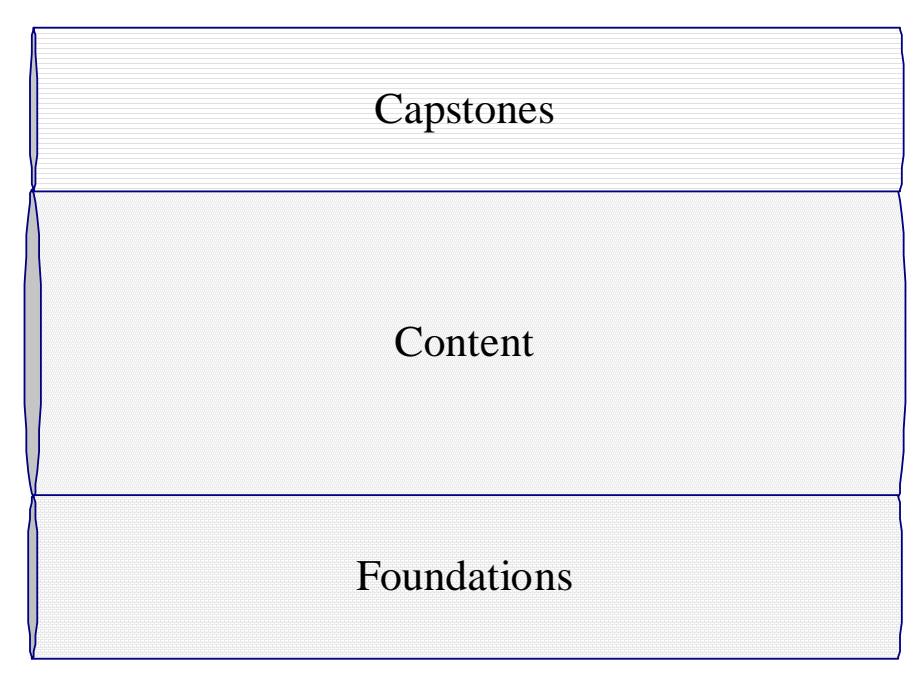

Figure 5: Tiered Organization

The traditional silo structure requires that many management functions be duplicated. Within each of the functional areas, there must be a department chair/division head and support services. Efforts to address collegewide problems require coordination between the silos. Scheduling of faculty can become problematic as student demographics shift from favoring one major to another. True multidisciplinary courses must address the mechanics of assigning the faculty involved.

Flipping the silos results in a horizontal organizational structure that can simplify the operations of a college while creating new opportunities for multidisciplinary education. The "walls" between the disciplines are gone. Problems and opportunities that previously crossed functional lines can now be dealt with in a holistic manner. Each of the tiers can focus on a specific aspect of the educational process. 


\section{THE TIERS}

The Foundations tier is designed to prepare students for the learning experience provided in later content courses. These courses can be conducted as seminars and utilize simulations and scenarios to impress upon students that business is truly a multidimensional experience. Seminar-like courses can be used as a means to improve student retention by creating social networks among the students. Such courses could also be designed to cover the introductory material which is currently presented in the college's common core.

The Content tier would be where the "traditional" courses from the various disciplines are taught. The benefit of bringing all these courses into a common tier is that now it will be easier to develop multidisciplinary courses since there are no silo walls to break through. Faculty members from several disciplines can now design and implement courses within a common managerial framework. Scheduling of faculty to meet the needs of the college is easier since all affected faculty are in the same tier. This integration of functional material is similar to what occurs in businesses. Changes and advances in one functional area can be immediately reflected in other functional areas. Cooperation can replace competition at all levels.

The Capstones tier would require multidisciplinary courses. Students who may have chosen to take courses primarily within a single discipline would complete their educational program working on the larger problems that they will soon face in the real world. Stress can be put on the development of speaking and presentation skills so that all students will be able to market themselves well to potential employers. These courses would "tie the ribbon on the package" that the student has experienced during his/her college career.

\section{THE FACULTY}

The faculty in the various tiers would be selected for their different skill sets. Some faculty members have stronger research skills, some have stronger teaching skills, and some interface better with the wider communities. The tier structure allows individuals with various personality types to work in an environment conducive to their relative strengths.

The faculty in the Foundations tier would be those with very strong people skills. These are the first faces the students will see. They need to be able to form a bond with the students and show the students that the college is truly interested in their success. It is likely that these faculty members will be more senior. These are the people who "know the system" and can project a parent figure to new students. Their role will be that of a mentor or counselor. Their experience and previous work with colleagues from other disciplines will give them the skills necessary to conduct multidisciplinary introductory exercises.

The Content faculty would be those who are actively involved in discipline-related or multidisciplinary research. New faculty members would likely be placed in this tier until they had developed their background in the institution and their instructional style. Individuals who excelled at research could stay in this tier and serve as resource persons. The key aspect of this tier is that all disciplines would be housed together. An accounting professor could have an office next to a marketing professor who is next to a management professor. New faculty members could be placed near their mentors. By eliminating the artificial barriers of the silos, faculty would be able to interact more easily. The cross-pollination of ideas and teaching techniques could develop true multidisciplinary educational opportunities while allowing all faculty members to still work within their own areas of interest.

The Capstones faculty could be drawn from all disciplines. These individuals would have a greater breadth of knowledge and/or more practical experience than their colleagues. Their goal would be to create an integrative experience for the students, one that transcends traditional disciplinary boundaries. They would be involved with team teaching or modular class structures and could employ various techniques from case studies to simulations and situational analysis. These individuals would also be the anchor point for the students who are about to enter the workforce. They would provide professional counseling and assure that each student had the skills necessary to be employable. 


\section{THE STUDENTS}

The concept of a tiered structure could also be applied to the student body. Students could be organized into cadres, based either on discipline or mixed disciplines. These cadres would generally follow the same course scheduling and share the same classes. This would allow the development of student networks both for personal and professional support. Students would develop a sense of identity within a larger framework.

\section{THE ADMINISTRATION}

Administration of a tiered college structure would be different than one with silos. Departments and divisions would no longer be competing with each other for resources. Plans with a broad scope would not need to be broken into small pieces for implementation. It would be possible to develop an overall integrated strategy geared towards providing a multidisciplinary education by using a multidisciplinary organizational structure.

One aspect of administration that would change would be in the area of the evaluation of faculty for annual reviews or promotion and tenure decisions. Each of the tiers requires a different set of skills and a different approach to the educational process. In some areas, teaching effectiveness and student interaction would be more important than depth of research. Evaluation procedures that recognized these differences would need to be developed, and faculty members would have to understand what factors would be used for their personal evaluation.

It would also be necessary for the administrators to adopt a concept of open communications and managerial transparency. The artificial walls of the silos no longer exist. There is a higher level of interaction between faculty members. It is unlikely that secrets could be kept. While this might challenge administrators who have learned their skills under the existing organizational systems, the broader interaction of highly educated and dedicated professionals should create the opportunities for everyone to succeed.

\section{CONCLUSION}

Higher education has always been difficult, and it is not getting any easier. Colleges of business are challenged with providing their students with multidisciplinary education in order to prepare them for an integrated, internationalized business world. Efforts to achieve this goal have been focused on modifying existing organizational parameters, but these modifications can be awkward. The time has come to take a step back and consider the entire structure of the organization. By flipping the college on its side and removing the existing organizational silos, the tiered structure has the capacity to address the problems of today and promises to provide the flexibility to meet the challenges of tomorrow.

\section{AUTHOR INFORMATION}

Dr. Dallas Brozik is the Kermit McGinnis Distinguished Professor in the College of Business at Marshall University. He is a professor of Finance, and his research interests include securities pricing, simulations and games, and pedagogical structures and applications. E-mail: brozik@ marshall.edu (Corresponding author)

Dr. Christopher M. Cassidy is an Assistant Professor of Management at Sam Houston State University, in Huntsville, TX. His research interests are in business policy and strategy, business ethics, and pedagogies related to experiential learning methods. Dr. Cassidy designs and uses experiential exercises and writes cases intended for use in the business curriculum. He has taught classes in strategic management, business policy, social issues in business, the political environment of business, leadership and teamwork, international business, and organizational development. E-mail: cassidy@shsu.edu.

\section{REFERENCES}

1. Athavale, M., Davis, R., \& Myring, M. (2008). The integrated business curriculum: An examination of perceptions and practices. The Journal of Education for Business, May/June, 83 (5), 295-301. 
2. Barney, J. (2002). Gaining and sustaining competitive advantage (2nd ed.). Upper Saddle River, NJ: Prentice Hall.

3. Bohanon, C. (2008). Persistent themes in colleges of business. The Journal of Education for Business, Mar/Apr, 83 (4), 239-245.

4. Bracken, P. (2008). Futurizing business education. The Futurist, Jul/Aug, 42 (4), 38-42.

5. Braun, N. (2004). Critical thinking in the business curriculum. The Journal of Education for Business, Mar/Apr, 79 (4), 232-236.

6. Brint, S., Proctor, K., Murphy, S., Turk-Bicakci, L., \& Hanneman, R. (2009). General education models: Continuity and change in the U.S. undergraduate curriculum, 1975-2000. The Journal of Higher Education, Nov/Dec, 80 (6), 605-642.

7. Chandler, A. (1962). Introduction, strategy and structure. In A. Chandler (Ed.), Strategy and structure: MIT Press.

8. DiMaggio, P., \& Powell, W. (1983). The iron cage revisited: Institutional isomorphism and collective rationality in organizational fields. American Sociological Review, 48, 147-160.

9. Hill, W. (1990). Curriculum integration and interdisciplinary teaching in a business school setting: Dilemmas for faculty. Education, Spring, 110 (3), 313-318.

10. Hitt, M., Ireland, R. \& Hoskisson, R. (2000). Strategic management: Competitiveness and globalization (4th ed.). Cincinnati, OH: South-Western College Publishing.

11. Hubball, H., \& Gold, N. (2007). The scholarship of curriculum practice and undergraduate program reform: Integrating theory into practice. New Directions for Teaching and Learning, Winter, 112, 5-14.

12. Junghagen, S. (2005). Working with business and industry to enhance curriculum development and student employability. New Directions for Institutional Research, Winter, 128, 69-81.

13. Peach, S. (2010). A curriculum philosophy for higher education: socially critical vocationalism. Teaching in Higher Education, August, 15 (4), 449-460.

14. Pharr, S. (2000). Foundational considerations for establishing an integrated business common core curriculum. The Journal of Education for Business, Sept/Oct, 76 (1), 20-23.

15. Pittendrigh, A. (2007). Reinventing the core: Community, dialogue, and change. The Journal of General Education, January, 56 (1), 34-56.

16. Smith, B., Hornsby, J., \& Kite, M. (2000). Broadening the business curriculum via a cross=disciplinary approach: A mobile unit on cultural diversity. Education, Summer, 120 (4), 713-721.

17. Taff, C. (1988). Why not a triple undergraduate major? Transportation Journal, Summer, 27 (4), $55-57$. 
NOTES 